\title{
The Use of WhatsApp as An Educational Communication Tool in Higher Education: Experiences of Nursing Students in Kavango East, Namibia
}

\author{
Vistolina Nuuyoma ${ }^{1}$, Nkosenhle Jermaine Mhlope $^{2} \&$ Leonard Chihururu $^{3}$ \\ ${ }^{1}$ University of Namibia, Senior Lecturer, School of Nursing, Namibia. \\ ORCiD https://orcid.org/0000-0002-5744-1355 \\ ${ }^{2}$ University of Namibia, School of Nursing, Namibia \\ ${ }^{3}$ University of Namibia, lecturer, School of Nursing, Namibia. \\ Correspondence: Vistolina Nuuyoma, University of Namibia, School of Nursing, Namibia. \\ E-mail: vnuuyoma@unam.na
}

Received: May 5, 2020

Accepted: July 16, 2020

Online Published: July 17, 2020

doi:10.5430/ijhe.v9n5p105

URL: https://doi.org/10.5430/ijhe.v9n5p105

\begin{abstract}
WhatsApp is the most popular networking site used by most university students for general purposes, and as a communication, collaborative and transactional tool in the teaching and learning process. However, experiences of its use among university students as an educational communication tool in low and resource-constrained settings have not been explored. Following a qualitative, descriptive, phenomenology approach, this study described and explored nursing students' experiences of the use of WhatsApp as an educational communication tool. Data were collected from 24 university nursing students who were conveniently sampled to participate in the focus group discussions; thereafter, data were analysed using qualitative content analysis. Whittemore, Chase and Mandle's primary criteria of validity in qualitative research, which include credibility, authenticity, criticality and integrity, were used to ensure the quality of the study. Ethical approval and permission were granted by the School of Nursing Research Ethics Committee. Informed consent was obtained from participants, and their anonymity and confidentiality were ensured. The findings revealed that WhatsApp is a beneficial communication tool but has effects on human behaviour. Moreover, connectivity and handset-related challenges were experienced by the students. Following these findings, it is concluded that WhatsApp is a suitable communication tool in higher education and in maintaining communities of practice among students and lecturers. Conversely, there is a need to educate students on mechanisms to mitigate its negative effects on human behaviours, such as disturbances, addiction, and lack of responses. Lastly, universities should consider partnering with network providers to improve connectivity among students and lecturers, as well as accessibility to affordable smartphones.
\end{abstract}

Keywords: communication tool, community of practice, higher education, nursing students, social networking, social learning, university students, WhatsApp

\section{Introduction}

WhatsApp Messenger is a popular social networking site in most, if not all, diverse corners of the world (Gasaymeh, 2017). It is an encrypted and instant messaging application supported by smartphones. It is designed to send and receive text messages, images, audio messages, videos, documents, user locations, and contacts using the internet. WhatsApp is also accessible through computers under the name 'WhatsApp Web'. It works through Web client, which means the web browser copies conversations and messages from the mobile device. Therefore, all messages are viewed on the mobile device and browser application, however, internet connectivity is required for accessing messages in the browser (Bouhnik \& Deshen, 2014). Other social networking sites used alongside WhatsApp include YouTube, Facebook, Twitter, WeChat, Wikis and online blogs (Bullock \& Webb, 2015). Although social networking sites are not principally designed for educational purposes, they share common characteristics which can be used to facilitate learning. Moreover, their use can ensure teamwork, peer communication - irrespective of geographical location and time of day - and they can be used for multimedia message sharing (AlFaris et al., 2018; Tang \& Hew, 2017). A scoping review revealed that WhatsApp has been used as a learning tool in university settings, healthcare settings and blended learning, and is used to successfully drive online discussions (Coleman \& O'Connor, 2019). 
WhatsApp is the most popular networking site used by most university students (AlFaris et al., 2018; Devi \& Tevera, 2014). This could be because it is easy to use, free, fast, and a convenient, personal mode of communication (Gasaymeh, 2017). Due to the advantages of WhatsApp over other forms of social media tools, it is considered an effective communication and collaborative tool in the teaching and learning process (Kufre \& Abe, 2017). The act of communicating embodies a process of conveying information, ideas, opinions and feelings from one individual to another, from an individual to a social group, and vice versa (Iordache-Platis \& Josan, 2009). Direct communication involves words and gestures, while indirect communication takes place through writing and other forms of mass media, including WhatsApp. Communication is a core component of sound relationships, collaboration and cooperation (Du Plessis, Joordaan \& Jali, 2018), which is required between students and educators. Communication is a crucial factor in education and a strong mediation mechanism with influence in human interactions. Within the educational context, it acts as an implementation mechanism through which education is deployed (Iordache-Platis \& Josan, 2009).

The nursing students at the university campus in northeast Namibia have been using WhatsApp as a communication tool since 2017. Each study level has its own group, created by class representatives. These groups serve as platforms for communicating subject-related and general issues with their lecturers and among students themselves. In light of this context, the researcher devised the following research question: What are nursing students' experiences of the use of WhatsApp as an educational communication tool at a university campus located in a resource-constrained setting? Thus, this study explored and described nursing students' experiences of the use of WhatsApp as an educational communication tool.

A community of practice, as proposed by Lave and Wenger (1991), was used as a framework for this study to account for the nursing students' experiences of WhatsApp as a communication tool in a university setting. A community of practice denotes a group of people who share a passion for something they do, or that concerns them; they learn how to do it better through regular interactions (Wenger-Trayner, 2015). It is based on the assumption that learning is not an individual endeavour but a social practice situated within cultural and historical contexts (Farnsworth, Kleanthous \& Wenger-Trayner, 2016). Therefore, individuals within the community of practice undertake activities together to solve problems, request information, seek experience, coordinate and find synergy, build an argument, develop confidence, discuss new developments, document projects, map and identify gaps in knowledge (Wenger-Trayner, 2015). Interactions in the community of practice occur in both formal and informal settings, provided they seek to share knowledge, collaborate in the creation of new knowledge, and have a shared identity among group members ( $\mathrm{Li}$ et al., 2009). According to Smith, Hayes and Shea (2017), the main principles that underpin the community of practice are the domain, the community, the practice, identity, participation and reification, joint enterprises, boundaries, mutual engagement and shared repertoire.

Social networking sites and applications, including WhatsApp, have been integrated into communities of practice, therefore facilitating what is called a 'virtual community of practice' (Pan et al., 2015). Gannon and Prothero (2018) stated that social networking sites, such as YouTube and Blogger, are communities of practice, rather than a means of interaction among group members. In light of the current study, students form WhatsApp groups as communities of practice. As observed through the practices of WhatsApp groups, members share a common identity linked to their study levels, which also serve as their community. Based on the above principles observed in the university WhatsApp groups, they are fit to be described as communities of practice, hence the use as a framework for the current study.

\section{Research Design}

A qualitative, descriptive, phenomenological approach (Husserl, as cited in Polit \& Beck, 2017) was used to describe and explore university nursing students' experiences of the use of WhatsApp as a communication tool. Descriptive phenomenological approach involves careful description of ordinary conscious experience of everyday life or description of things as people experience them (Polit \& Beck, 2017).

\section{Methods}

\subsection{Research Setting}

The study was conducted in Kavango East, at the campus of a public university in Namibia. The campus offers programmes from three faculties, namely Education, Health Science, Economic and Management Sciences. The School of Nursing, under the Faculty of Health Science, offers only one programme, a four-year undergraduate bachelor of nursing science (clinical) honours. WhatsApp is widely used as a communication tool for all students in the School of Nursing. 


\subsection{Participants and Sampling Procedures}

A convenient sample $(\mathrm{n}=24)$ of nursing students registered at the northeast campus was obtained to collect data. Convenient sampling denotes that subjects are included in the study because they happened to be in the right place at the right time (Grove, Burns \& Gray, 2013). In this study, the researcher recruited available nursing students until data saturation was reached; when participants began to repeat issues and additional data became redundant (Hennink, Kaiser \& Weber, 2019). The recruitment of subjects was based on the sampling criteria, which comprised second, third- and fourth-year level students. First-year nursing students were not included in the study as data were collected in April 2019, only a few months into the start of the academic year. Therefore, the time first-year nursing students spent at the academic institution was considered insufficient for them to be included in the study. The sample consisted of 13 males and 11 females, with ages ranging from 19 to 35 years. Ten students were in their second year of study, eight were in their third year, and six were fourth-year students. A total of 221 students were registered for second, third- and fourth-year study levels in the nursing programme for the academic year 2019.

\subsection{Data Collection and Analysis}

Data were collected through four focus group discussions which took place in the lecture halls at the university campus. Students were recruited by briefing them about the study in the lecture halls. A time and date for discussions was arranged with those who agreed to participate in the study. The researcher moderated the discussion according to a pre-arranged list of semi-structured questions, which were open-ended in nature; this facilitated deeper exploration of research experiences and ensured that valuable data were not overlooked (Minnaar, 2018). Each group consisted of six participants, and an audio recording was made of each session to prevent the loss of information from participants and ensure better data scrutiny. Each participant received a code in the form of alphabetical letters and numbers to apply in place of their real names to ensure anonymity. The duration of the discussions was 40 minutes on average. All discussions were conducted in English, as this is the official language understood and preferred by all participants. Prior to data analysis, all audio recordings from the focus group discussions were transcribed.

Data were analysed following a qualitative content analysis method (Polit \& Beck, 2017). This involves the identification of prominent themes by breaking data into smaller units and naming the units according to the content they represent.

\subsection{Data Quality Measures}

Primary criteria of validity in qualitative research, which include credibility, authenticity, criticality and integrity, were used to ensure the quality of the study (Whittemore, Chase \& Mandle, 2001). These criteria are essential to all qualitative inquiries. Data were collected until saturation was reached. Moreover, peer debriefing took place with co-researchers, and member checking was performed with study participants; this ensured the credibility of the study. Credibility refers to the extent to which the researchers have produced results that reflect the views of participants (Grove \& Gray, 2019). Integrity was achieved by documenting all steps taken during the study. This is to ensure that interpretations are valid and based on the data collected. Verbatim transcription was done of all data from the focus group discussions, which ensured authenticity. Authenticity criteria reveals the extent to which researchers fairly and faithfully display a range of realities (Polit \& Beck, 2017). Lastly, criticality was achieved by the researchers engaging in critical thinking before taking any steps in the study. Criticality refers to the researcher's critical appraisal of every decision made throughout the research process (Polit \& Beck, 2017).

\subsection{Ethical Considerations}

Ethical approval and permission was granted by the School of Nursing Research Ethics Committee (SoNEC02/2019). Study participants gave written informed consent, no force or any form of coercion was used during the recruitment process, and participants also had the right to withdraw from the study at any point. Anonymity was achieved by not recording participants' names; instead, codes were used during data collection and in the final report. Confidentiality was ensured by conducting focus group discussions in a closed lecture hall, and all participants were told not to share information outside the discussion venue. No potential risks or violation of rights were endured as a result of participation in this study.

\section{Findings}

The three main themes that emerged from participants' responses are: WhatsApp is a beneficial communication tool; effects of WhatsApp on human behaviour; and connectivity and handset-related challenges were experienced. Table 1 displays the main themes and their sub-themes. The findings are described in detail, and participants' verbatim quotes are provided to support the description of findings. 
Table 1. Summary of study findings

Main themes

1. WhatsApp is a beneficial

communication tool

2. Effects of WhatsApp on human

behaviour

3. Connectivity and handset-related

challenges
Sub-themes

1.1 Allowing synchronised discussions

1.2 Promoting freedom of expression

1.3 Sharing academic and non-academic materials

with several recipients

1.4 WhatsApp is convenient for users

2.1 Allowing discrimination

2.2 Causing disturbances

2.3 Lack of responses from group members

2.4 Promoting addiction

3.1 Poor internet connectivity

3.2 Specifications of handsets

\section{Theme 1: WhatsApp is a beneficial communication tool}

Participants reported positive experiences in their use of WhatsApp, thus indicating it is a beneficial communication tool in higher education. The benefits participants experienced were in terms of discussions, freedom of expression, sharing of content, and convenience for registered WhatsApp users.

\section{Sub-theme 1.1: Allowing synchronised discussions}

This study revealed that WhatsApp allows for impromptu discussions by randomly sending messages and exchanging information between many users. This was done by organising a discussion time, or posting a message on the WhatsApp group for users available online to respond immediately. Participants appreciated the fact that they were able to contact their lecturers and classmates to enquire about subject-related matters and get feedback immediately. Participants shared:

"I like WhatsApp, you can have live discussions with your classmates and lecturers, actually the good part is getting immediate feedback on any announcement made or course-related information not clear to you" (P2 FGD1 (Note 1)

"Lecturers make urgent announcement for example on postponement of a test and students get the message or reply immediately" (P3 FGD3)

\section{Sub-theme 1.2: Promoting freedom of expression}

Joy and relief were experienced by participants using WhatsApp as a communication tool as it afforded them an opportunity to interact with other users. Moreover, participants indicated that WhatsApp allowed them to express their views and opinions freely without any feeling of intimidation, as opposed to face-to-face communication.

"It increases confidence, speak freely and shy people are able to express themselves, this is very difficult when it comes to face-to-face communication” (P4 FGD1)

"I like this WhatsApp platform; we share ideas and teach each other openly" (P5 FGD2)

This implied that students did not feel judged based on the messages they communicated through WhatsApp.

\section{Sub-theme 1.3: Sharing academic and non-academic materials with several recipients}

The study revealed that WhatsApp, as a communication tool, allows users to send and receive large-sized documents, as well as multiple documents, media and other content, among a large pool of users. This was experienced as beneficial because, on average, the nursing cohort at the campus where the data were collected consists of 70 
students. Therefore, WhatsApp allowed them to share material with several cohort members at a time.

"Lecturers and class representatives send announcements, some relate to module content and some just general information" (P4 FGD3)

"We share slides of notes with others, it is very easy to send and get notes at once" (P3 FGD2)

"One can just post the information on WhatsApp group and everyone will get it" (P4 FGD1)

\section{Sub-theme 1.4: WhatsApp is convenient for users}

The study participants shared that using WhatsApp in their academic errands was reasonably cheap because of its affordability in terms of data bundles.

"WhatsApp does not really use a lot of data, like me I only spend $N \$ 50.00$ per week and is enough to access all information that is shared on all WhatsApp groups. I just have to make sure I don't use my data unnecessary like viewing friends'status or downloading irrelevant documents people share sometimes" (P3 FGD3)

Easy access to WhatsApp was also experienced by the participants. They were able to send and receive messages of interest anytime and anywhere; all that is needed is internet reception and a device with WhatsApp installed. Easy accessibility to WhatsApp was also associated with its downloading process, which is fast and contains clear steps to follow; no subsequent signing in is required from users. Moreover, it is speedy in sending and receiving content, which was also appreciated by participants.

"You receive information sent, doesn't matter where you are, as long as you have access to internet" (P5 FGD3)

"The good thing is you do not have to be physically present to receive information shared" (P5 FGD1)

"When you download WhatsApp, it does not ask for a lot of details, all you need is cellphone number and one two three...you're done." (P4 FGD2)

Participants also appreciated the multi-functionality of WhatsApp, as it allows functions such as voice calls, video calls, small group calls and voice notes. This makes it suitable for longer voice calls and shorter meetings, which is affordable for students; other communication tools require stronger network connectivity and more advanced devices to connect.

"There is actually a lot you can do with WhatsApp, you can voice and video call using mobile data, viewing and sharing statuses" (P1 FGD2)

"I find other tools somehow complicated to use, some require valid email addresses, some do not connect on mobile data, need you to be connected from WIFI, NO, that is complicated for students!" (P2 FGD4)

\section{Theme 2: Effects of WhatsApp on human behaviour}

Exploring student nurses' experiences of the use of WhatsApp as an educational communication tool revealed that there was a sense of negativity encountered with regard to its effects on users' behaviour. These were associated with discrimination, lack of responses, disturbance, and the promotion of addiction.

\section{Sub-theme 2.1: Allowing discrimination}

With regard to discrimination, participants indicated that in their WhatsApp groups, users tend to have side-long conversations, excluding other members of the groups. Additionally, some users specified in their responses to whom the messages were directed, making other users feel discriminated against. Equally, group members write hate-speech and discriminatory words and emojis directed at individuals or a group of individuals.

"We were encouraged to join WhatsApp groups with our classmates but sometimes really, ah... they are useless. Students write messages to discriminate others, I remember there was a message posted I you are not from my region keep quite already" (P6 FGD4)

\section{Sub-theme 2.2: Causing disturbances}

The study revealed that WhatsApp might cause a disturbance among student users. This was due to some users sharing non-academic and irrelevant materials, such as comedy, pornography and current affairs not of interest to all students. In addition, some users may share information or call at inappropriate times, such as early morning or late at night, disturbing users' sleep and study times.

"Some people post irrelevant things like sex videos, provocative pictures, local news and really do we have to share that on university-affiliated WhatsApp groups? It is very disturbing!" (P5 FGD4)

"I personally receive call and text asking unimportant issues which do not concern academics" (P4 FGD3) 
"I have a problem with people who call or share messages as late as 23 h00 or as early as $02 \mathrm{~h} 00$ AM, for me that's the time I sleep and study, no time to chat" (P1 FGD2)

\section{Sub-theme 2.3: Lack of responses from group members}

The sharing of information on WhatsApp was valued by participants. However, participants became anxious in the utilisation of WhatsApp when there was a delay in reaction or a non-confirmation of acknowledging the sent message in cases where prompt responses were anticipated. Conversely, a concern was raised about the lack of responses from the receiver of messages, despite evidence that the receiver read the message.

"I just do not like it when they do not respond to messages. I enquired if a lecturer is available for class but nobody responded, I could clearly see who read my message but they chose to ignore me, including the lecturers, as a result I missed that class" (P3 FGD4)

\section{Sub-theme 2.4: Promoting addiction}

Participants described that prolonged use of WhatsApp leads to addiction for the users. This was evidenced by students' eagerness and pleasure at seeing what is shared by other users and chatting with them.

"There was a time I can't stay away from my phone at all because of WhatsApp, every time I just want to check my messages, check people's statuses and chat with people" (P5 FGD1)

"WhatsApp is exciting to use for communication but can develop into a negative habit" (P4 FGD2)

\section{Theme 3: Connectivity and handset-related challenges}

In Namibia, residents make use of $3 \mathrm{G}$ and $4 \mathrm{G}$ network mode. In very remote areas, access to the internet is gained via 3G network mode only. This poses a problem of low and a lack of internet connectivity in some parts of the country. Participants described their experiences of the use of WhatsApp as it related to internet connectivity and the handsets accessible to students.

\section{Sub-theme 3.1: Poor internet connectivity}

For normalisation in the functioning of WhatsApp, an extreme link is required between the network sim card and the servers of the cable data providers. Participants described negative experiences linked to internet connectivity, which negatively affects communication via WhatsApp.

"We have a problem with internet connectivity, network is very poor especially during the day. It gets better during late nights and early morning hours but who want to chat that time?" (P6 FGD3)

"I like to use WhatsApp, it is a good App to use but the problem is internet connectivity. This internet is always tripping, you are in a middle of conversation, internet just goes off, when you try to contact the other person, they are already offline and conversation is interrupted" (P6 FGD2).

Due to a lack of and low internet connectivity, it is difficult to know if the user's phone is offline due to a flat battery, or if there are insufficient funds to access mobile data.

"If you sent a message, it is difficult to recognize if the other user do not have access to internet or didn't charge their battery. The App doesn't give this feedback" (P5 FGD4)

\section{Sub-theme 3.2: Specifications of handsets}

Although WhatsApp is downloadable and compatible for use through smartphones, there are still some smartphones that do not support it. Participants described this as a negative experience because, as students, it is costly to get compatible devices. Moreover, some smartphones have low memory capacity and are therefore unable to download WhatsApp as their cellphones do not have enough storage capacity.

"Some students do not have phones compatible with WhatsApp, in other words, I can say it is not accessible to all due to limitations of the handsets" (P3 FGD2)

"My phone does not have large memory space, I deleted most important information in my phone just to keep WhatsApp..., otherwise I am missing out a lot on important communications" (P1 FGD4)

The current study revealed that communicating through WhatsApp requires devices with powerful batteries. Students who live in areas without power supply only remain connected for a few hours because they are only able to charge their cellphone batteries at the university premises.

"WhatsApp sucks battery at a very abnormal levels for us who resides in Donkerhoek and other places without proper electricity we are suffering, you only get the message when you reach school because the cellphone was off" 


\section{(P6 FGD4)}

\section{Discussion}

WhatsApp is the most popular networking site used by most university students for non-academic social networking, and as a collaborative and transactional tool in the teaching and learning process (AlFaris et al., 2018; Devi \& Tevera, 2014; Kufre \& Abe, 2017; Mbukusa, 2018; Naidoo \& Kopung, 2016). However, experiences of its use among university students as an educational communication in low and resource-constrained settings, such as rural areas, have not been studied. The current study explored and described nursing students' experiences of the use of WhatsApp as an educational communication tool, based on Lave and Wenger's (1991) community of practice as its framework. It revealed that students find WhatsApp to be a beneficial tool, which is consistent with the findings of Church and De Oliveira (2013) and Robles, Guerrero, Llinás and Montero (2019). The students in the current study described the benefits in terms of accessibility to users, sharing of content among many users at one time, and promoting freedom of expression. Similarly, Kustijono and Zuhri (2018) found that WhatsApp is easily accessible, easy to operate, cheap, not time-consuming, it allows the sharing of material, and it allows students to study anytime and anywhere. Nursing students are required to attend clinical practice for the duration of their training, therefore, participants in the current study appreciated that WhatsApp allows them to access learning materials and communicate with their peers, irrespective of whether some are in clinical practice or at the university premises. Along similar lines, Naidoo and Kopung (2016) also reported that WhatsApp supports communication regardless of the students' locations and it facilitates learning at students' own pace and time. Students' accessibility to learning materials anytime, anywhere, and in various formats, is likely to enhance deep learning capabilities and help them build their own knowledge (Amry, 2014).

WhatsApp's convenience was also reported by Gachago et al., (2015) who revealed that WhatsApp allows connectivity between students and lecturers across different contexts of their lives. The convenience of WhatsApp reported in the current study was also associated with its ability to perform multiple functions. This correlates with the study of Alshammari, Parkes and Adlington (2017), who reported that students appreciated WhatsApp's ability to handle a range of tasks, including texts, images, audio and video. Moreover, as a benefit of WhatsApp revealed from this study, freedom of expression was experienced as WhatsApp allowed users to express their opinions without any intimidation. Although freedom of expression was not mentioned in their study, Robles et al., (2019) found that WhatsApp created a sense of peace of mind due to frequent contact with peers. The same authors also determined that WhatsApp chats mostly consisted of messages such as expressions of thanks, motivating and apologetic messages, which indicate a free communication spirit, relating to freedom of expression among users. A previous study by Alshammari et al., (2017) reported that the use of WhatsApp fosters trust among students and lecturers, and helps facilitate communication free of embarrassments when errors were made. Additionally, WhatsApp was found to promote positive freedom among students (Naidoo \& Kopung, 2016). These findings indicate that WhatsApp has an advantage of nurturing interpersonal relationships in the higher education environment. Also, on the benefits of WhatsApp, allowing synchronised discussions was experienced in this study since students were free to set up chat times and have live discussions among themselves and lecturers. Similarly, Gashegu et al., (2019) reported that most WhatsApp conversations happened when lecturers were available and active online, therefore facilitating synchronised discussions. The synchronised online discussions among students on social networks provide an added cognitive value with opportunities to construct and share knowledge in educational contexts (Amry, 2014).

Despite the benefits of WhatsApp that were discussed, university nursing students experienced that it affected human behaviours. While students in the context of the current study associated WhatsApp with discrimination of individuals in the groups, WhatsApp was found to be one way for students to seek freedom from cultural and social restrictions imposed by the society in which they live (Gasaymeh, 2017). There was a concern of lack of responses from WhatsApp users in the current study, especially in the groups created for scholarly communication. Similarly, Bouhnik and Deshen (2014) reported that students do not make efforts to participate in WhatsApp conversations, thereby hindering interaction among the students and their lecturers. As an effect on human behaviour, WhatsApp is disruptive to students when communications are sent at inappropriate times or when it contains an inappropriate message. Inappropriate timing of the messages, unnecessary messages and disrobing messages are negative experiences of the use of WhatsApp in the educational context reported in literature (Cetinkaya, 2017). In the current study, the timing was inappropriate when messages were sent late-night (after 23h00) and too early in the morning (02h00). The inappropriate messages not tolerated by students consisted of pornography, violence, vulgar and current affairs not related to their education processes.

While WhatsApp is reported to increase interests, motivation, critical thinking and participation among students in 
educational matters (Gravan, Regaña \& Noguera, 2018), the current study revealed that it might also promote addiction among users. The users get addicted in terms of keeping their devices close and communicating on social media in general, not necessarily on matters related to teaching and learning. The constant presence of technology is known to lead to dependency, creating an urge to keep the mind occupied (Bullock \& Webb, 2015). WhatsApp's effect on human behaviour, as revealed in this study, is in contrast to the principles and key activities of the communities of practice, which are mostly intended to advance the whole group and not for personalised intentions that make members feel individually affected.

Key concerns revealed in the current study related to internet connectivity and handset-related challenges that were experienced by university nursing students. Although WhatsApp is freely downloadable to smartphones through Play stores, it requires internet access to be downloaded and used. The challenge of poor connectivity experienced by WhatsApp users in the current study is common in this context; generally, the town and its surroundings have poor internet connectivity affecting the use of WhatsApp. Although other studies highlighted that WhatsApp does not require advanced equipment and infrastructure (Gasaymeh, 2017), this study revealed that users are required to have smartphones with specifications that support WhatsApp. This could be because, in the context of the study, there are cellphone users who still use 'old tech' phones which do not connect to the internet. The challenge for students who do not use smartphones was also reported by Bouhnik and Deshen (2014), therefore forming a barrier to the use of WhatsApp in the educational context. Moreover, memory capacities and the strength of batteries were found to be challenging factors in the use of WhatsApp in this study. This is in accordance with Kustijono and Zuhri's (2018) findings that technical constraints occur related to consuming memory, time and eyestrain. Similarly, Bouhnik and Deshen (2014) revealed that one of the challenges of WhatsApp is the flooding of messages, which cause memory space to be filled with unimportant information and media.

The data were collected April to May 2019, a period towards the end of semester one. Some potential participants approached by the researchers were not available to participate in the study due to demands of academic activities such as submissions of assignments and preparations for tests. Those who agreed to participate experienced difficulty in identifying suitable times for focus group discussions. Consequently, the researchers had to acquaint themselves with the students' academic schedules and the university calendar to approach students during open slots and times where fewer activities were scheduled. Although the university campus offers programmes from three faculties, participants in this study were all from the School of Nursing. This is also considered a limitation as their experiences on the use of WhatsApp as a communication tool may differ from those of students in other faculties. However, the researchers' intentions were to pilot the project with the School of Nursing students as it had fewer students and WhatsApp groups, in comparison to the other faculties, hence their exclusion in the current study.

It is recommended that universities partner with network providers to improve connectivity for students and lecturers. Additionally, to relieve the problem of a lack of accessibility to smartphones compatible with WhatsApp, universities could partner with retailers for students to buy smartphones at discounted prices. Future research should consider exploring lecturers' influence on the manner in which students converse in their WhatsApp groups. Additionally, other research studies may also assess the effects of WhatsApp on learning performance and motivation among students in low and resource-constrained contexts, including the setting of the current study.

\section{Conclusion}

Findings revealed the benefits of WhatsApp and its effects on human behaviour while highlighting internet connectivity and handset specifications as challenges for students using WhatsApp as an educational communication tool. Considering the benefits revealed from the findings of the current and previous studies, there is potential for WhatsApp to be a suitable communication tool in higher education contexts, serving as communities of practice for students and lecturers. However, there is a need to educate university students on mechanisms to mitigate its negative effects, such as disturbances, addiction, and lack of responses. Lastly, the universities should be empowered to partner with network providers to improve connectivity for students and lecturers, as well as accessibility to affordable and compatible smartphones with most networking applications, including WhatsApp.

\section{Acknowledgement}

The authors are grateful to the students who participated in this study despite their busy academic schedules.

\section{References}

AlFaris, E., Irfan, F., Ponnamperuma, G., Jamal, A., Van der Vleuten, C., Al Maflehi, N. \& Ahmed, A. M. A. (2018). The pattern of social media use and its association with academic performance among medical students. Medical Teacher, 40(sup1), S77-S82. https://doi.org/10.1080/0142159X.2018.1465536 
Alshammari, R., Parkes, M. \& Adlington, R. (2017). Using WhatsApp in EFL Instruction with Saudi Arabian University Students. Arab World English Journal, 8(4), 68-84. https://doi.org/10.24093/awej/vol8no4.5

Amry, A. B. (2014). The impact of WhatApp mobile social learning on the achievement and attitudes of female students compared with face to face learning in the classroom. European Scientific Journal, 10(22), 116-136. Retrieved from http://eujournal.org/index.php/esj/article/view/3909

Bouhnik, D. \& Deshen, M. (2014). WhatsApp Goes to School: Mobile Instant Messaging between Teachers and Students. Journal of Information Technology Education: Research, 13, 217-231. https://doi.org/10.28945/2051

Bullock, A. \& Webb, K. (2015). Technology in postgraduate medical education: A dynamic influence on learning? Postgraduate Medical Journal, 91(1081), 646-650. https://doi.org/10.1136/postgradmedj-2014-132809

Cetinkaya, L. (2017). The impact of whatsapp use on success in education process. International Review of Research in Open and Distance Learning, 18(7), 59-74. https://doi.org/10.19173/irrodl.v18i7.3279

Church, K. \& De Oliveira, R. (2013). What's up with WhatsApp? Comparing mobile instant messaging behaviors with traditional SMS. MobileHCI 2013 - Proceedings of the 15th International Conference on Human-Computer Interaction with Mobile Devices and Services, 352-361. https://doi.org/10.1145/2493190.2493225

Coleman, E. \& O'Connor, E. (2019). The role of WhatsApp ${ }^{\circledR}$ in medical education; A scoping review and instructional design model. BMC Medical Education, 19(1), 1-13. https://doi.org/10.1186/s12909-019-1706-8

Devi, T. S. \& Tevera, S. (2014). Use of social networking site in the University of Swaziland by the health science students: A Case study. Journal of Information Management, 1(1), 19-26. Retrieved from www.pacificresearchpublications.com

DuPlessis, E., Joordaan, E. \& Jali, M. (2018). Communication in a health care unit. In K. Jooste (Ed.). The Principles and Practice of Nursing and Health Care (2nd ed, p. 229). Pretoria: Van Schaick.

Farnsworth, V., Kleanthous, I. \& Wenger-Trayner, E. (2016). Communities of Practice as a Social Theory of Learning: A Conversation with Etienne Wenger. British Journal of Educational Studies, 64(2), 139-160. https://doi.org/10.1080/00071005.2015.1133799

Gachago, D., Strydom, S., Hanekom, P., Simons, S. \& Walters, S. (2015). Crossing Boundaries: Lecturers' Perspectives on the Use of Whatsapp To Support Teaching and Learning in Higher Education. Progressio: South African Journal for Open and Distance Learning Practice, 37(1), 172-187. https://doi.org/10.25159/0256-8853/579

Gannon, V. \& Prothero, A. (2018). Beauty bloggers and YouTubers as a community of practice. Journal of Marketing Management, 34(7-8), 592-619. https://doi.org/10.1080/0267257X.2018.1482941

Gasaymeh, A.-M. (2017). University Students' use of Whatsapp and their Perceptions Regarding its Possible Integration into their Education. Global Journal of Computer Science and Technology, 17(1), 1-11.

Gashegu, J., Mfashingabo, F., Shingiro, A., Mugisha, D., Nyauma, N. \& Kiswezi, A. (2019). Using WhatsApp Discussion Groups in Learning at Higher Education Institutions: The Experience with Level 1 University of Rwanda Medical Students in Anatomy. Rwanda Journal of Medicine and Health Sciences, 2(1), 30-33. https://doi.org/https://dx.doi.org/10.4314/rjmhs.v2i1.6

Gravan, P., Regaña, C. \& Noguera, M. (2018). Academic whatsapp groups as alternative communication and motivation systems in higher education. Espacios, 39(10).

Grove, SK., Burns, N. \& Gray, J. (2013). The practice of nursing research: Appraisal, synthesis, and generation of evidence. In Elsevier (7th ed.). Missouri: Elsevier Ltd.

Grove, S. \& Gray, J. (2019). Understanding nursing research: Building an evidence-based practice. In Elsevier (7th ed). Missouri: Elsevier Ltd.

Hennink, M. M., Kaiser, B. N. \& Weber, M. B. (2019). What Influences Saturation? Estimating Sample Sizes in Focus Group Research. Qualitative Health Research, 29(10), 1483-1496. https://doi.org/10.1177/1049732318821692

Iordache-Platis, M. \& Josan, I. (2009). Communication efficiency within higher education institutions: The case of Romania. European Research Studies Journal, 12(2), 55-66. https://doi.org/10.35808/ersj/220

Kufre, P. \& Abe, E. (2017). Effectiveness of Whatsapp as a collaborative tool for learning among undergraduate 
students in university of Uyo , Akwa Ibom state. International Journal of Advanced Education and Research, 2(5), 43-46.

Kustijono, R. \& Zuhri, F. (2018). The use of Facebook and WhatsApp application in learning process of physics to train students' critical thinking skills. IOP Conference Series: Materials Science and Engineering, 296(1). https://doi.org/10.1088/1757-899X/296/1/012025

Lave, J. \& Wenger, E. (1991). Situated learning: Legitimate peripheral participation. https://doi.org/10.2307/2804509

Li, L. C., Grimshaw, J. M., Nielsen, C., Judd, M., Coyte, P. C. \& Graham, I. D. (2009). Evolution of Wenger's concept of community of practice. Implementation Science, 4(1), 1-8. https://doi.org/10.1186/1748-5908-4-11

Mbukusa, N. R. (2018). Perceptions of students' on the Use of WhatsApp in Teaching Methods of English as Second Language at the University of Namibia. Journal of Curriculum and Teaching, 7(2), 112. https://doi.org/10.5430/jct.v7n2p112

Minnaar, A. (2018). Data gathering and analysis. In K. Jooste (Ed.). The principles and practice of nursing and health care (2nd ed, pp. 341-348). Pretoria: Van Schaick Publisher.

Naidoo, J. \& Kopung, K. J. (2016). Exploring the Use of WhatsApp in Mathematics Learning: A Case Study. Journal of Communication, 7(2), 266-273. https://doi.org/10.1080/0976691x.2016.11884907

Pan, Y., Xu, Y. C., Wang, X., Zhang, C., Ling, H. \& Lin, J. (2015). Integrating social networking support for dyadic knowledge exchange: A study in a virtual community of practice. Information and Management, 52(1), 61-70. https://doi.org/10.1016/j.im.2014.10.001

Polit, D. \& Beck, C. (2017). Nursing research: Generating and assessing evidence for nursing practice. In Wolters Kluwer (10th ed). Philadelphia.

Robles, H., Guerrero, J., Llinás, P. \& Montero, P. (2019). Online teacher-student interactions using WhatsApp in a law course. Journal of Information Technology Education, 18, 231-252. https://doi.org/https://doi.org/10.28945/4321

Smith, S. U., Hayes, S. \& Shea, P. (2017). A critical review of the use of Wenger's community of practice (CoP) theoretical framework in online and blended learning research, 2000-2014. Online Learning Journal, 21(1), 209-237. https://doi.org/10.24059/olj.v21i1.963

Tang, Y. \& Hew, K. F. (2017). Is mobile instant messaging (MIM) useful in education? Examining its technological, pedagogical, and social affordances. Educational Research Review, 21(November 2018), 85-104. https://doi.org/10.1016/j.edurev.2017.05.001

Wenger-Trayner, E. (2015). Communities of practice a brief introduction. Retrieved from https://wenger-trayner.com/

Whittemore, R., Chase, S. \& Mandle, L. (2001). Validity in qualitative research. Qualitative Research, 2(4), 522-537. https://doi.org/https://doi.org/10.1177/104973201129119299

\section{Note}

Note 1. Participant's code 